\title{
Relationship of Psychical Reliability and Motivational Component of Social and Psychological Compatibility of Sportsmen-Players
}

\section{Взаимосвязь психической надежности и мотивационного компонента социально- психологической совместимости спортсменов-игровиков}

\author{
Aleksandr Gavrilovich \\ Senior Lecturer of the \\ Department of Psychology
}

\author{
Александр Гаврилович \\ старший викладач \\ кафедри психології
}

\section{E-mail: agavrilovich@tut.by \\ orcid.org/0000-0001-9178-029X \\ Researcher ID: G-8743-2019}

\begin{abstract}
Educational Institution «Brest State University named after A. S. Pushkin», Brest, Republic of Belarus 21, Kosmonavtiv Boulevard, Brest, 224016
\end{abstract}

Установа освіти «Брестський державний університет ілені О.С. Пушкіна», л. Брест, Республіка Білорусь бульвар Космонавтів, 21, м. Брест, 224016

Original manuscript received April 15, 2019 Revised manuscript accepted May 06, 2019

\section{ABSTRACT}

The problem of the influence of interpersonal relations on the maintenance of psychical stability and success of the competitive potential of athletes and teams is solved in the article. The systematization of theoretical approaches to the understanding of reliability in sports activities is presented. Interpersonal relationships are considered in the context of socio-psychological compatibi- 
lity, which has motivational component as one of the leading ones. The aim of the research was to study the relationship of psychical reliability and motivational component of the social and psychological compatibility of athletesplayers. To achieve this goal, a battery of psychodiagnostic techniques was used. 70 athletes of professional-level game sports took part voluntarily in the empirical study. As a result of the correlation analysis, we identified specific interrelations both in the structure of the psychical reliability of athletesplayers - between emotional stability and self-regulation, motivational and energetic component, stability - noise immunity, and between the components of psychical reliability (motivational and energetic, stability - noise immunity) and individual parameters of the motivational component of social and psychological compatibility. It has been established that internal, pivotal, motive-forming motives for sports, which set a purposeful activity for selfrealization and athletic performance (the need for achievement, fight, selfimprovement - the motives of the stage of sportsmanship), have the dominant meaning for the formation of high psychical reliability, distinguishing a successful athlete, while situational motives arising from external sources relating to an individual or a task (material needs, the need for encouragement, approval, etc.) are not interconnected with the components of psychical reliability, as indirect or secondary.

Key words: interpersonal relations, psychical reliability, social and psychological compatibility, motivational sphere of personality, athlete, sports activity, sports team.

\section{Введение}

В настоящее время важнейшим условием решения проблемы психологического обеспечения подготовки спортсменов и команд к высокорезультативным и стабильным выступлениям является системный анализ требований, предъявляемых деятельностью к психике спортсменов и, в частности, к уровням ее активности - психическим состояниям.

Анализ исследований, посвященных вопросам психических состояний в рамках психологической науки, демонстрирует значительный интерес к ним со стороны отечественных и зарубежных ученых. В одной из первых и значительных работ в данном направлении Н. Д. Левитов определяет психическое состояние как «целостную харак- 
теристику психической деятельности за определенный период времени, показывающую своеобразие протекания психических процессов в зависимости от отражаемых предметов и явлений действительности, предшествующего состояния и психических свойств личности» (Левитов, 1964: 21). В дальнейшем исследованием проблемы психических состояний человека занимались В. А. Ганзен (Ганзен, 1986), Е. П. Ильин (Ильин, 1983), А. О. Прохоров (Прохоров, 2011) и др.

В отечественной психологии спорта особое внимание исследователей (В. Л. Марищук, К. К. Платонов, Е. А. Плетницкий (Марищук, Платонов \& Плетницкий, 1968), А. Ц. Пуни (Пуни, 1969), О. В. Черникова (Черникова, 1980) и др.) уделяется изучению отрицательных психических состояний (стресс, фрустрация, состояние напряженности, состояние психического пресыщения), способствующих формированию нервно-психической неустойчивости как «свойства психики, характеризующегося широким диапазоном признаков неблагополучия в нервнопсихической сфере; с повышением степени ее выраженности связывается высокий риск срыва нервно-психической деятельности под влиянием неблагоприятных факторов» (Марищук, 2001: 41). В зарубежной психологии спорта, на наш взгляд, акцент в данном аспекте смещен в сторону изучения многочисленных источников возникновения психических состояний спортсменов. Дифференцированы и детально анализируются ситуационные и личностные детерминанты психических проявлений, что находит отражение в теории «драйва» J. T. Spence, K. W. Spence (Spence \& Spence, 1966) и работах ее критиков R. Martens, R. S. Vealey, D. Burton (Martens, Vealey \& Burton, 1990), теории «разноуровнего беспокойства» D. Gould, V. Krane (Gould \& Krane, 1992), теории «катастрофы» L. Hardy (Hardy, 1990), теории «реверсивности» Ј. Н. Kerr (Kerr, 1985) и др.

Комплексным подходом к анализу проблемы психических состояний в спорте, с целью повышения нервно- 
психической устойчивости спортсменов, выступает ее изучение в процессе формирования психической надежности субъектов спортивной деятельности (В. А. Плахтиенко, Ю. М. Блудов (Платхиенко \& Блудов, 1983), В. Л. Марищук (Марищук, 2001), Н. А. Худадов (Худадов, 1968) и др.). Значительная часть работ, в которых отмечается актуальность оценки психических состояний спортсменов в прогнозе успешности спортивной деятельности, направлена на исследование их готовности к соревнованиям и психической надежности - «сложного интегративного качества личности, обеспечивающего устойчивость основных психических механизмов в экстремальных условиях тренировки и соревнований» (Уляева, 2014: 102).

Анализ литературы позволяет констатировать, что проблема надежности стала предметом научного изучения в середине XX в. Понятие «надежность» первоначально соотносилось с наиболее важными требованиями, предъявляемыми к техническим средствам деятельности, что обусловило ее глубокое изучение в рамках технических наук, позже - инженерной психологии. В дальнейшем проблема надежности активно исследуется в рамках самых разных отраслей психологической науки.

Современная спортивная наука не предлагает единого подхода к пониманию надежности в спорте. В то же время, обзор ее определений исследователями спортивной деятельности позволяет систематизировать их в следующие группы (руководствуясь особенностями предмета исследования):

1. Надежность как безотказное выступление спортсменов (без привязки к видам спорта) в соревнованиях со стабильной результативностью в пределах заданного периода времени. При этом эффективность деятельности спортсмена рассматривается в качестве основного компонента надежности: А. Ф. Вендрих (Вендрих, 1974), Л. П. Матвеев (Матвеев, 1977) и др. 
2. Надежность как степень технической подготовленности и технической устойчивости спортсменов различных видов спорта к воздействию сбивающих факторов соревнований, позволяющая ему выступать в конкретном соревновании не ниже заданного уровня: В. В. Давыдов, П. А. ЗЖоров (Давыдов \& З゚оров, 1977) и др.

3. Надежность как уровень профессионального мастерства, который обусловливает уровень результативности деятельности спортсменов в сложных условиях соревнований: В. М. Дьячков, Н. А. Худадов (Дьячков \& Худадов, 1977) и др.

4. Психическая надежность как комплексное состояние, определяющее эффективность соревновательной активности спортсменов индивидуальных и командных видов спорта: В. А. Платхиенко, Ю. М. Блудов (Платхиенко \& Блудов, 1983), В. Э. Мильман (Мильман, 1983) и др. Психическая надежность, являясь качественной характеристикой состояния общей надежности, отражает устойчивость функционирования психического механизма управления спортивной деятельностью (Мильман, 1983). Психическая надежность рассматривается в качестве потенциальных резервов спортсмена (Платхиенко \& Блудов, 1983).

Несмотря на достаточно большой интерес ученых и практиков к проблеме психической надежности в спорте, на наш взгляд, влияние фактора межличностных отношений на обеспечение психической стабильности и успешности соревновательного потенциала спортсмена и команд, их взаимосвязь изучены недостаточно. Анализ теоретико-эмпирических исследований в области спортивной психологии свидетельствует, что проблема межличностных отношений в спорте изучается в контексте развития взаимоотношений в системах «тренер - спортсмен» и «спортсмен - спортсмен», социально-психологического климата, межличностной совместимости, сплоченности, сработанности и взаимопонимания (Ю. А. Коломейцев 
(Коломейцев, 1984), Б. Дж. Кретти (Кретти, 1983) и др.). Особую актуальность проблема межличностных отношений приобретает в контексте изучения внутрикомандных взаимоотношений в спорте. Так, авторитетный румынский спортивный психолог М. Эмпуран утверждает, что у игроков командных видов спорта, действующих сообща, должны быть выражены такие психологические качества, как эвристические способности, коммуникабельность, способность к сотрудничеству (Курамшин, 2003). Немецкий психолог K. Kohl отмечает, что наличие противоречивых тенденций поведения у спортсменов командных видов спорта: с одной стороны, это коллективный поиск путей достижения цели и объединение усилий ради запланированного результата; с другой стороны, стремление руководить другими и «показать себя» зрителям (Кретти, 1978).

В подходах к пониманию феномена совместимости, классификации и определению ее видов (уровней) мы полностью разделяем взгляды Ю. А. Коломейцева (Коломейцев, 1984). Ученый, придерживаясь традиционной в отечественной психологии классификации видов совместимости (социальная, психологическая и психофизиологическая), в качестве интегрального предлагает вид социально-психологической совместимости - как «единство взглядов и мнений на нормы и требования общества, одинаковые потребности и систему ценностей, синхронность психомоторных реакций, уровень возбуждения и торможения, сходство по таким личностным качествам, как экстра-интроверсия, синтония, мотивация, внимание, скорость переработки информации и т. д.» (Коломейцев, 2004: 120). Данная трактовка определяет методологию и логику построения нашего исследования, целью которого является изучение взаимосвязи психической надежности и социально-психологической совместимости в спортивной деятельности, обусловливает набор психодиагностического инструментария. 


\section{Задача статьи}

В статье представлено обсуждение данных, полученных в итоге корреляционного анализа: 1) между параметрами психической надежности спортсменов-игровиков; 2) между составляющими психической надежности и мотивации спортсменов как ведущего компонента социально-психологической совместимости в спортивной команде.

\section{Методы и методики исследования}

Эмпирическое исследование осуществлялось на базе факультета физического воспитания Брестского государственного университета имени А. С. Пушкина. Выборку составили 70 спортсменов игровых видов спорта профессионального уровня ( $\mathrm{n}=70)$ : футболисты-мужчины дублирующего состава клуба «Динамо-Брест», волейболисты мужской команды «Западный Буг» (Брест), волейболистки женской команды «Прибужье» (Брест), баскетболистки женской команды «ЦОР Виктория» (Брест). Участие в исследовании было добровольным.

Для измерения психической надежности спортсменов была использована методика «Психическая надежность спортсмена» В. Э. Мильмана. Ученый, определяя психическую надежность как «устойчивость функционирования основных психических механизмов в сложных соревновательных условиях», выделяет следующие ее компоненты: «соревновательную эмоциональную устойчивость, саморегуляцию, мотивационно-энергетический компонент, стабильность и помехоустойчивость» (Марищук, 1984: 83). Созданная им методика позволяет измерять выраженность у отдельного спортсмена каждой из указанных составляющих.

Мотивационный компонент социально-психологической совместимости спортсменов исследовался нами с применением следующих методик:

- методики «Диагностика направленности личности» Б. Басса (опросник В. Смейкла и М. Кучера) - для выявле- 
ния направленности личности спортсмена: личностной (на себя), деловой (на задачу), коллективистской (на взаимодействие) (Коломейцев, 1984);

- методики «Диагностика личности на мотивацию к успеху» Т. Элерса - для изучения мотивационной направленности личности на достижение успеха (Волков, 2002);

- методики «Мотивы спортивной деятельности» Е. А. Калинина - для определения и оценки выраженности отдельных мотивов спортивной деятельности (Коломейцев, 2004);

- методики «Диагностика степени удовлетворения основных потребностей» (метод парных сравнений В. В. Скворцова) - для изучения актуальности базовых потребностей (потребностей, мотивирующих в данный момент (неудовлетворенные потребности), а также удовлетворенных и частично удовлетворенных потребностей, не играющих решающую роль на данном этапе): материальных, потребности в безопасности, социальных (межличностных) потребностей, потребности в признании и в самовыражении (Фетискин, 2002).

Обработка первичных данных осуществлялась с помощью корреляционного анализа с использованием статистической программы SPSS (V.16).

\section{Результаты и дискуссии}

В результате были выделены следующие специфические взаимосвязи в структуре психической надежности спортсменов-игровиков:

1) значимая положительная корреляция между выраженностью соревновательной эмоциональной устойчивости и уровнем саморегуляции $(r=0,318, \mathrm{p} \leq 0,01)$. Эмоциональная устойчивость, выступая важнейшим условием достижения запланированного уровня эффективности психической и физической работоспособности в стрессовых условиях спортивных соревнований, является результатом длительного тренировочного процесса и серьезной 
системной работы над собой. Эмоциональная устойчивость, определяющая самообладание, управление своими действиями, чувствами, переживаниями, поступками, обладание способностью сознательно регулировать свое поведение в экстремальных условиях, напрямую зависит от достигнутого уровня саморегуляции, показателями которой выступают «умение правильно осознавать и оценивать свое эмоциональное состояние, умение влиять на него, в частности, посредством словесных самоприказов, умение перестроиться в ходе соревновательной борьбы, развитие функции самоконтроля над своими действиями и т. д.» (Марищук, 1984: 84). Полученные нами результаты в полной мере соотносятся с данными, представленными в работах В. И. Моросановой (Моросанова, 2007), посвященных разработке различных аспектов проблемы саморегуляции личности, которая отмечает, что именно саморегуляция обеспечивает мобилизацию и интеграцию психологических особенностей человека для достижения целей деятельности и поведения, способствует выработке гармоничного поведения. На ее основе развивается способность управлять своими эмоциональными состояниями сообразно реализации поставленной цели, направлять свое поведение в соответствии с задачами;

2) значимая положительная корреляция между выраженностью соревновательной эмоциональной устойчивости и стабильностью-помехоустойчивостью ( $\mathrm{r}=0,318$, $\mathrm{p} \leq 0,01)$, т. е. спокойный эмоциональный фон выступления, трезвая и рациональная оценка спортсменом внешних событий и запланированной программы действий, оптимальная регуляция посредством эмоций энергетического потенциала в предстартовой ситуации и в ходе соревновательной борьбы обусловлены отсутствием спонтанных колебаний спортивной формы и техники спортсмена, его устойчивостью к воздействию разноплановых по механизму возникновения и степени трудности препятствий, сопутствующих спортивным соревнованиям. Например, 
в спортивно-игровой деятельности речь может идти о преодолении таких внешних препятствий, как неожиданность реакции болельщиков, непредсказуемость тактических замыслов соперника, ошибочность собственных или командных действий. Совершенно не случайно в работах А. Ц. Пуни (Пуни, 1969) акцентируется такое направление предсоревновательной подготовки спортсмена, как специальная подготовка к встрече с соревновательными помехами и упражнение в их преодолении;

3) значимая положительная взаимосвязь между выраженностью мотивационно-энергетического компонента и соревновательной эмоциональной устойчивостью $(\mathrm{r}=0,318, \mathrm{p} \leq 0,01)$. Уровень соревновательной мотивации, отражающий состояние внутренних побудительных сил, способствующих полной реализации спортсменом своих возможностей в ходе соревновательной борьбы, определяет адекватность эмоциональной оценки ситуации и соразмерность эмоциональных реакций в условиях соревновательного выступления. Следовательно, в стрессовых ситуациях соревновательной деятельности, когда физическое и психическое напряжение достигает пиковых значений, оптимальный уровень мотивации приобретает решающее значение в обеспечении необходимой эмоциональной устойчивости спортсмена. Полученные результаты соотносятся с содержанием законов оптимума мотивации Йеркса - Додсона.

Сходство мотивации членов спортивной команды выступает и в качестве базового структурного компонента социально-психологической совместимости. Именно мотивационная сфера личности спортсмена определяет осознанный вектор движения спортсмену и команде на пути к достижению запланированных целей. С. Л. Рубинштейн рассматривает цель как предмет удовлетворения потребности, когда предмет становится носителем желаний и возможных целей субъекта (Рубинштейн, 1976). Однако в условиях спортивной командной деятельности задача 
достижения совместного результата упрощается при наличии схожей мотивации (Коломейцев, 1984). Ведущему значению таких феноменов, как мотивация и направленность личности, принципиально важных для реализации задач оценки и формирования профессиональной деятельности спортсмена, значительное внимание уделено в работах Р. А. Пилояна (Пилоян, 1984).

В результате корреляционного анализа нами были установлены следующие специфические взаимосвязи между уровнем психической надежности и выраженностью различных параметров мотивационной сферы спортсменов-игровиков:

1) значимая положительная корреляция между выраженностью у спортсмена мотивации к успеху и уровнем мотивационно-энергетического компонента психической надежности $(\mathrm{r}=0,247, \mathrm{p} \leq 0,05)$, т. е. оптимальный рост мотивационной направленности на достижение успеха обусловливает интенсивность целенаправленной активности спортсмена. Как следствие, умеренно сильная ориентация на успех способствует более полному проявлению возможностей спортсмена, стремлению к любой форме соревновательной активности, полной отдаче в ходе тренировочного и соревновательного процессов;

2) значимая отрицательная корреляция между доминированием личностной направленности (на себя) и уровнем стабильности и помехоустойчивости $(r=-0,36, p \leq 0,01)$, т. е. преобладание у спортсмена мотивов собственного благополучия, излишнее стремление к личностному первенству и престижу, увлеченность удовлетворением своих притязаний вне зависимости от интересов других спортсменов негативно отражается на устойчивости функционального состояния и двигательных компонентов в ситуациях различной напряженности спортивной командной деятельности;

3) значимая положительная корреляция между выраженностью у спортсмена потребности в достижении и 
уровнем стабильности и помехоустойчивости $(\mathrm{r}=0,257$, $\mathrm{p} \leq 0,05)$. Выраженная у спортсмена потребность в достижении характеризуется общим стремлением к постоянному поиску путей повышения результативных показателей его профессиональной деятельности, протекающей в условиях помех;

4) значимая положительная корреляция между выраженностью у спортсмена потребности в борьбе и уровнем мотивационно-энергетического компонента психической надежности $(\mathrm{r}=0,293, \mathrm{p} \leq 0,05)$ отражает существенную взаимосвязь между смыслообразующей для деятельности спортсмена потребностью в борьбе (преодолении препятствий, достижении успеха, в состязании) и развитием его мотивации и высокой активности. В данном контексте потребность в борьбе можно рассматривать как способ достижения цели в спорте. Как следствие, мотивация приобретает более конкретное, целевое соревновательное значение. Развитость состязательности, как совокупности различных мотивов, побуждает спортсмена не просто принимать участие в соревнованиях, а двигаться к победе, выступать с отдачей, желанием, выраженным эмоциональным зарядом;

5) значимая положительная корреляция между выраженностью у спортсмена потребности в борьбе и уровнем стабильности и помехоустойчивости $(\mathrm{r}=0,275, \mathrm{p} \leq 0,05)$, т. е. увеличение значимости для спортсмена потребности в борьбе сопряжено с повышением его эмоциональной устойчивости и способностью эффективно противостоять воздействию стресс-факторов. Влиянием на спортсмена различных разноплановых помех характеризуется любой этап соревновательной борьбы. Механизм их влияния состоит в воздействии на эмоциональную сферу спортсмена, что влечет негативные переживания, неадекватное поведение и снижение общей результативности деятельности. Как показывает практика, явное преимущество в соревнованиях имеют те спортсмены, которые оптимально мотивирова- 
ны на борьбу, успех которой в значительной степени обусловлен развитием способности противодействия помехам (помехоустойчивости). В. А. Мильман среди основных составляющих стабильности - помехоустойчивости отмечает «степень сформированности той системы действий, которую необходимо реализовать спортсмену в экстремальной ситуации борьбы» (Мильман, 1983: 30);

6) значимая положительная корреляция между выраженностью у спортсмена потребности в самосовершенствовании и уровнем мотивационно-энергетического компонента психической надежности $(\mathrm{r}=0,256, \mathrm{p} \leq 0,05)$. П. Вейс, рассуждая о философских аспектах спорта, отмечает, что спортивную деятельность можно рассматривать в качестве одного из немногих путей самосовершенствования личности, «используя физические возможности для достижения определенных вершин, обычно недоступных тем, кто занимается интеллектуальной деятельностью» (Кретти, 1978: 104). Таким образом, стремление спортсмена к осознанному развитию себя, личностному и карьерному росту - самосовершенствованию и самоактуализации - стимулирует целенаправленную активность спортсмена, способствует точной постановке профессиональных целей и их достижению;

7) значимая положительная корреляция между выраженностью у спортсмена потребности в самосовершенствовании и уровнем стабильности-помехоустойчивости $(\mathrm{r}=0,263, \mathrm{p} \leq 0,05)$, т. е. целенаправленное стремление спортсмена к самосовершенствованию, работе над собой способствует формированию личностных качеств, позволяющих достичь значительного роста стабильности-помехоустойчивости, что проявляется в снижении спонтанных колебаний спортивной формы, техники спортсмена, минимизации влияния неожиданных раздражителей на выступление, росте уверенности в себе. 


\section{Выводы}

Полученные результаты свидетельствуют о наличии взаимосвязи мотивационного компонента социально-психологической совместимости и психической надежности спортсмена. При этом необходимо особенно отметить, что доминирующее значение для формирования высокой психической надежности, отличающей успешного спортсмена, имеют внутренние, стержневые, смыслообразующие для спорта мотивы, задающие целенаправленную активность на реализацию себя и спортивный результат (потребности в достижении, в борьбе, самосовершенствовании мотивы стадии спортивного мастерства), в то время как ситуативные мотивы, возникшие из внешних по отношению к индивиду или задаче источников (материальные потребности, потребность в поощрении, одобрении и др.), не взаимосвязаны с компонентами психической надежности и являются косвенными или второстепенными.

Таким образом, эмоциональное напряжение как психическое состояние, оптимальный уровень которого определяет психическую надежность спортсмена, формируется под влиянием таких ведущих факторов, как интенсивность мотивации и неопределенность протекания деятельности. Последний можно рассматривать в качестве доминирующего стрессора в деятельности спортсменов игровых видов спорта, умение успешно справляться с которым оказывает влияние на уровень надежности как отдельного спортсмена, так и спортивной команды в целом.

\section{Литература}

Вендрих А. Ф. Проблема надежности спортсмена в психологическом аспекте. Теория и практика физической культуры. 1974. № 2. C. $53-56$.

Ганзен В. А. Системное описание функционирования психики человека в актуальном времени. Вестник ЛГУ. Сер. 6. 1986. Вып. 1. С. 65.

Давыдов В. В., Жоров П. А. О некоторых принципах построения учебнотренировочного процесса в связи с проблемой надежности. Психическая надежность спортсменов высокого класса и методы ее 
совершенствования / Под ред. К. П. ЗКарова, В. А. Платхиенко. Москва, 1977. Т. 1. С. 92-96.

Дьячков В. М., Худадов Н. А. Проблемы технического мастерства как факторы психической надежности деятельности спортсменов. Москва, 1977. Вып. 1. С. 21-29.

Ильин Е. П. Психология спорта. Современные направления в психологии. Ленинград : ЛГУ, 1983. 96 с.

Коломейцев Ю. А. Взаимоотношения в спортивной команде. Москва : Физкультура и спорт, 1984. 128 с.

Коломейцев Ю. А. Социальная психология спорта: учеб.-метод. пособие. Минск : БГПУ, 2004. 292 с.

Кретти Б. Д. Психология в современном спорте. Москва : Физкультура и спорт, 1978. $224 \mathrm{c.}$

Левитов Н. Д. О психических состояниях человека. Москва : Просвещение, 1964. 343 с.

Марищук В. Л., Блудов Ю. М., Платхиенко В. А., Серова Л. К. Методики психодиагностики в спорте. Москва : Просвещение, 1984. $191 \mathrm{c}$.

Марищук В. Л., Евдокимов В. И. Поведение и саморегуляция человека в условиях стресса. Санкт Петербург : Издательский дом «Сентябрь», 2001. 260 с.

Марищук В. Л., Платонов К. К., Плетницкий Е. А. Напряженность в полете. Москва : Воениздат, 1968. 117 с.

Матвеев Л. П. Основы спортивной тренировки. Москва : Физкультура и спорт, 1977. 280 с.

Мильман В. Э. Стресс и личностные факторы регуляции деятельности. Стресс и тревога в спорте: леждународный сборник научных статей / Сост. Ю. Л. Ханин. Москва : Физкультура и спорт, 1983. C. 24-46.

Моросанова В. И., Аронова Е. А. Самосознание и саморегуляция поведения. Москва : Изд-во «Институт психологии РАН», 2007. 213 с.

Пилоян Р. А. Мотивация спортивной деятельности. Москва : Физкультура и спорт, 1984.104 с.

Платхиенко В. А., Блудов Ю. М. Надежность в спорте. Москва : Физкультура и спорт, 1983. 176 с.

Практикум по спортивной психологии / Под ред. И. П. Волкова. СанктПетербург : Питер, 2002. 288 с.

Психолого-педагогическое сопровождение спортивной деятельности в контексте самореализации личности: монография / [Л. Г. Уляева, Е. В. Мельник и др.]; под общ. ред. Л. Г. Уляевой. Москва : Издатель Мархотин П. Ю., 2014. 236 с.

Психология состояний: учебное пособие / Под ред. А. О. Прохорова. Москва : Когито-центр, 2011. 624 с. 
Пуни А. Ц. Психологическая подготовка к соревнованию в спорте. Москва : Физкультура и спорт, 1969. 88 с.

Рубинштейн С. Л. Проблемы общей психологии. Москва : Педагогика, 1976. $365 \mathrm{c}$.

Теория и методика физической культуры: учебник / Под ред. Ю. Ф. Курамшина. Москва : Советский спорт, 2003. 464 с.

Фетискин Н. П., Козлов В. В., Мануйлов Г. М. Социально-психологическая диагностика развития личности и малых групп. Москва : Изд-во Института психотерапии, 2002. 490 с.

Худадов Н. А. Психологическая подготовка боксера. Москва : Физкультура и спорт, 1968. 102 с.

Черникова О. А. Соперничество, риск и самообладание в спорте. Москва : Физкультура и спорт, 1980. 104 с.

Gould, D., \& Krane, V. (1992). The arousal-athletic performence relationship: Current status and future directions. In T. Horn (Eds.). Advences in sport psychology. Champaign, IL : Human Kinetics, pp. 119-141.

Hardy, L. (1990). A catastrophe model of performance in sport. In J. G. Jones \& L. Hardy (Eds.). Stress and performance in sport. Chichester, England : Wiley, pp. 81-106.

Kerr, J. H. (1985). The experience of arousal: A new basis for studying arousal effects in sport. Journal of Sport Sciences, 3, 169-179.

Martens, R., Vealey, R. S., \& Burton, D. (Eds.) (1990). Competitive anxiety in sport. Champaign, IL : Human Kinetics, pp. 117-190.

Spence, J. T., \& Spence, K. W. (1966). The motivational components of manifest anxiety: Drive and drive stimuli. In C. D. Spielberger (Eds.). Anxiety and behavior. New York : Academic Press.

\section{References}

Vendrih, A. F. (1974). Problema nadezhnosti sportsmena v psihologicheskom aspekte [The problem of reliability of the athlete in the psychological aspect]. Teorija i praktika fizicheskoj kul'tury - Theory and practice of physical culture, 2, 53-56 [in Russian].

Ganzen, V. A. (1986). Sistemnoe opisanie funktsionirovanija psihiki cheloveka v aktual'nom vremeni [System description of the functioning of the human psyche in the current time]. Vestnik LGU - Newsletter of Leningrad State University, 1 (Ser. 6 ), 65 [in Russian].

Davydov, V. V., \& Zhorov, P. A. (1977). O nekotoryh printsipah postroenija uchebno-trenirovochnogo protsessa v svjazi s problemoj nadezhnosti [On some principles of the construction of the training process in connection with the problem of reliability]. Psihicheskaja nadezhnost' sportsmenov vysokogo klassa i metody ee sovershenstvovanija-Psychical reliability of high-class athletes and methods of its improvement, 1, 92-96 [in Russian]. 
D’jachkov, V. M., \& Hudadov, N. A. (1977). Problemy tehnicheskogo masterstva kak faktory psihicheskoj nadezhnosti dejatel'nosti sportsmenov [Problems of technical skill as factors of psychical reliability of athletes ]. (Vols. 1), (pp. 21-29). Moskva [in Russian].

Il'in, E. P. (1983). Psihologija sporta. Sovremennye napravlenija v psihologii [Sports psychology. Modern trends in psychology]. Leningrad : LGU [in Russian].

Kolomejtsev, Ju. A. (1984). Vzaimootnoshenija $v$ sportivnoj komande [Relationships in the sports team ]. Moskva : Fizkul'tura i sport [in Russian].

Kolomejtsev, Ju. A. (2004). Sotsial'naja psihologija sporta [Social psychology of sport]. Minsk : BGPU [in Belarus].

Kretti, B. D. (1978). Psihologija v sovremennom sporte [Psychology in modern sport]. Moskva : Fizkul'tura i sport [in Russian].

Levitov, N. D. (1964). O psihicheskih sostojanijah cheloveka [On the mental state of the person]. Moskva : Prosveshchenie [in Russian].

Marishchuk, V. L., Bludov, Ju. M., Plathienko, V. A., \& Serova, L. K. (1984). Metodiki psihodiagnostiki $v$ sporte [Methods of psychodiagnostics in sports ]. Moskva : Prosveshchenie [in Russian].

Marishchuk, V. L., \& Evdokimov, V. I. (2001). Povedenie i samoreguljatsija cheloveka $v$ uslovijah stressa [Behavior and self-regulation of a person under stress]. Sankt-Peterburg: Izdatel'skij dom «Sentjabr'» [in Russian].

Marishchuk, V. L., Platonov, K. K., \& Pletnitskij, E. A. (1968). Naprjazhennost' $v$ polete [Tension in flight]. Moskva : Voenizdat [in Russian].

Matveev, L. P. (1977). Osnovy sportivnoj trenirovki [Basics of sports training]. Moskva : Fizkul'tura i sport [in Russian].

Mil'man, V. E. (1983). Stress i lichnostnye faktory reguljatsii dejatel'nosti [Stress and personal factors of activity regulation]. J. L. Hanin (Eds.). Stress i trevoga $v$ sporte - Stress and anxiety in sport. Moskva : Fizkul'tura i sport, (pp. 24-26) [in Russian].

Morosanova, V. I., \& Aronova, E. A. (2007). Samosoznanie i samoreguljatsija povedenija [Self-awareness and self-regulation of behavior]. Moskva : Izd-vo «Institut psihologii RAN» [in Russian].

Pilojan, R. A. (1984). Motivatsija sportivnoj dejatel'nosti [Motivation of sports activities ]. Moskva : Fizkul'tura i sport [in Russian].

Plathienko, V. A., Bludov, Ju. M. Nadezhnost'v sporte [Reliability in sport]. Moskva : Fizkul'tura i sport [in Russian].

Volkov, I. P. (Eds.) (2002). Praktikum po sportivnoj psihologii [Practical course in sports psychology]. Sankt-Peterburg : Piter [in Russian].

Uljaeva, L. G., \& Mel'nik, E. V. (2014). Psihologo-pedagogicheskoe soprovozhdenie sportivnoj dejatel'nosti $v$ kontekste samorealizatsii lichnosti [Psychological and pedagogical support of sports activities in 
the context of self-realization]. Moskva : Izdatel' Marhotin P. Ju. [in Russian].

Prohorov, A. O. (Eds.) (2011). Psihologija sostojanij [Psychology of States]. Moskva : Kogito-tsentr [in Russian].

Puni, A. Ts. (1969). Psihologicheskaja podgotovka $k$ sorevnovaniju v sporte [Psychological preparation for competition in sports]. Moskva : Fizkul'tura i sport [in Russian].

Rubinshtejn, S. L. (1976). Problemy obshchej psihologii [Problems of general psychology]. Moskva : Pedagogika [in Russian].

Kuramshin, Ju. F. (Eds.) (2003). Teorija i metodika fizicheskoj kul'tury [Theory and methods of physical culture]. Moskva : Sovetskij sport [in Russian].

Fetiskin, N. P., Kozlov, V. V., \& Manujlov, G. M. (2002). Sotsial'no-psihologicheskaja diagnostika razvitija lichnosti i malyh grupp [Socio-psychological diagnosis of personality development and small groups]. Moskva : Izd-vo Instituta psihoterapii [in Russian].

Hudadov, N. A. (1968). Psihologicheskaja podgotovka boksera [Psychological training of boxer]. Moskva : Fizkul'tura i sport [in Russian].

Chernikova, O. A. (1980). Sopernichestvo, risk i samoobladanie $v$ sporte [Competition, risk and self-control in sports]. Moskva : Fizkul'tura i sport [in Russian].

Gould, D., \& Krane, V. (1992). The arousal-athletic performance relationship: Current status and future directions. T. Horn (Eds.). Advances in sport psychology. Champaign, IL : Human Kinetics, pp. 119-141.

Hardy, L. (1990). A catastrophe model of performance in sport. J. G. Jones \& L. Hardy (Eds.). Stress and performance in sport. Chichester, England : Wiley, pp. 81-106.

Kerr, J. H. (1985). The experience of arousal: A new basis for studying arousal effects in sport. Journal of Sport Sciences, 3, 169-179.

Martens, R., Vealey, R. S., \& Burton, D. (Eds.) (1990). Competitive anxiety in sport. Champaign, IL : Human Kinetics, pp. 169-179.

Spence, J. T., \& Spence, K. W. (1966). The motivational components of manifest anxiety: Drive and drive stimuli. C. D. Spielberger (Eds.). Anxiety and behavior. New York : Academic Press.

Гаврилович Олександр. Взаємозв'язок психічної надійності та мотиваційного компонента соціально-психологічної сумісності спортсменів ігрових видів спорту

\section{АНОТАЦІЯ}

У статті розкрито проблему впливу міжособистісних відносин на забезпечення психічної стабільності й успішності змагального потенціалу спортсменів і команд. Представлено систематизацію теоретич- 
них підходів до розуміння надійності в спортивній діяльності. Міжособистісні відносини розглядаються в контексті соціально-психологічної сумісності, що має в якості одного з провідних компонентів мотиваційний. Метою дослідження було вивчення взаємозв'язку психічної надійності та мотиваційного компонента соціально-психологічної сумісності спортсменів ігрових видів спорту. Для досягнення поставленої мети застосовано низку психодіагностичних методик. В емпіричному дослідженні добровільно взяли участь 70 спортсменів ігрових видів спорту професійного рівня. У результаті кореляційного аналізу нами виявлено специфічні взаємозв'язки як у структурі психічної надійності спортсменів ігрових видів спорту - між емоційною стійкістю і саморегуляцією, мотиваційно-енергетичною складовою, стабільністюзавадостійкістю, так і між складовими психічної надійності (мотиваційно-енергетичною, стабільністю-завадостійкістю) й окремими параметрами мотиваційного компонента соціально-психологічної сумісності. Установлено, що домінуюче значення для формування високої психічної надійності, що відрізняє успішного спортсмена, мають внутрішні, стрижневі для спорту мотиви, які визначають цілеспрямовану активність на реалізацію себе і спортивний результат (потреби в досягненні, в боротьбі, самовдосконаленні - мотиви стадії спортивної майстерності), в той час як ситуативні мотиви, що виникли із зовнішніх стосовно індивіда або завдання джерел (матеріальні потреби, потреби в заохоченні, схваленні тощо), не взаємопов'язані з компонентами психічної надійності, будучи непрямими або другорядними.

Ключові слова: міжособистісні відносини, психічна надійність, соціально-психологічна сумісність, мотиваційна сфера особистості, спортсмен, спортивна діяльність, спортивна команда.

\section{Гаврилович Александр. Взаимосвязь психической надежности и моти- вационного компонента социально-психологической совместимости спортсменов-игровиков}

\section{АННОТАЦИЯ}

В статье раскрыта проблема влияния межличностных отношений на обеспечение психической стабильности и успешности соревновательного потенциала спортсменов и команд. Представлена систематизация теоретических подходов к пониманию надежности в спортивной деятельности. Межличностные отношения рассматриваются в контексте социально-психологической совместимости, имеющей 
в качестве одного из ведущих компонентов мотивационный. Целью исследования было изучение взаимосвязи психической надежности и мотивационного компонента социально-психологической совместимости спортсменов-игровиков. Для достижения поставленной цели применялся ряд психодиагностических методик. В эмпирическом исследовании добровольно приняли участие 70 спортсменов игровых видов спорта профессионального уровня. В результате корреляционного анализа нами выявлены специфические взаимосвязи как в структуре психической надежности спортсменов-игровиков-между эмоциональной устойчивостью и саморегуляцией, мотивационно-энергетической составляющей, стабильностью-помехоустойчивостью, так и между составными частями психической надежности (мотивационно-энергетической, стабильностью-помехоустойчивостью) и отдельными параметрами мотивационного компонента социально-психологической совместимости. Установлено, что доминирующее значение для формирования высокой психической надежности, отличающей успешного спортсмена, имеют внутренние, стержневые, смыслообразующие для спорта мотивы, задающие челенаправленную активность на реализацию себя и спортивный результат (потребности в достижении, в борьбе, самосовершенствовании - мотивы стадии спортивного мастерства), в то время как ситуативные мотивы, возникшие из внешних по отношению к индивиду или задаче источников (материальные потребности, потребности в поощрении, одобрении и др.), не взаимосвязаны с компонентами психической надежности, являясь косвенными или второстепенными.

Ключевые слова: межличностные отношения, психическая надежность, социально-психологическая совместимость, мотивационная сорера личности, спортсмен, спортивная деятельность, спортивная команда. 